\title{
Hospital Acquired Infections with Multiresistant Microorganisms: Can We Escape the Postantibiotic Era?
}

\author{
Guggenbichler $\mathbf{S}^{1}$, M Hell ${ }^{2}$ and Guggenbichler JP ${ }^{3 *}$ \\ ${ }^{1}$ Division of vascular surgery and endovascular surgery of the University of Salzburg, Austria \\ ${ }^{2}$ MEDILAB OG-Department of Clinical Microbiology and Hygiene - Teaching Laboratory of the Paracelsus Medical University, \\ Salzburg, Austria \\ ${ }^{3}$ AmiStec. Laboratory, Kössen, Austria
}

*Corresponding author: Guggenbichler JP, Department or Pediatrics, AmiSTec GMbH und Co KG, Kössen, Austria

\begin{tabular}{|c|c|}
\hline ARTICLE INFO & ABSTRACT \\
\hline Received: 盉 July 01, 2020 & Citation: Guggenbichler S, M Hell, Guggenbichler JP. Hospital Acquired Infections with \\
\hline Published: 慧 September 18, 2020 & $\begin{array}{l}\text { Multiresistant Microorganisms: Can We Escape the Postantibiotic Era?. Biomed J Sci \& } \\
\text { Tech Res 30(3)-2020. BJSTR. MS.ID.004967. }\end{array}$ \\
\hline
\end{tabular}

\section{Introduction}

World wide, millions of patients are affected annually by healthcare-associated infections (HCAI), impacting up to 8000 patients in European Hospitals on any given day [1]. The Centers for Disease Control (CDC) estimates that 2 million U.S. patients per year acquire a hospital-related infection. These infections cause 90,000 deaths each year [2,3]. This represents not only a public health risk, but also an economic burden with an average cost of $\$ 47,000$ per patient to treat. The added cost to hospitals is $\$ 4.8$ billion annually for extended care treatment $[4,5]$. Bacteria and other microbes evolve in response to their environment and inevitably develop mechanisms to resist being killed by antibiotics and disinfectants [6]. For many decades the problem was manageable as the growth of resistance was slow and the pharmaceutical industry continued to create new antimicrobial agents. The evolution of antibiotic resistance is now occurring at an alarming rate and is outpacing the development of new countermeasures.

A number of reasons like the

a) Indiscriminate use of antibiotics for viral infections

b) Use of antibiotics in animal husbandry

have been incriminated [7,8]. However, these reasons although important contribute only modestly to the dramatic increased emergence of resistant microorganisms. The emergence of multi resistant microorganisms however developed into a dramatic situation. Biofilm formation and subinhibitory concentrations of disinfectants contribute to this phenomenon [911]. More than 8000 publications in the international literature describe the resistance of microorganisms against disinfectants and in addition 678 publications describe the cross resistance with antibiotics. Contaminated surfaces contribute substantially to the transmission of hospital pathogens and the spread of multi resitant microorganisms [12]. Disinfection of surfaces with disinfectants is not constructive any more as ample evidence exists for tolerance of microorganisms to sublethal levels of various disinfectants e.g quaternary ammonium compounds (QAC) i.e. benzalkonium chloride as well as chlorhexidine, hexadecylpyridinium and cetrimide [13]. The resistance of QAC based disinfectants to antibiotics is conferred by the resistance determinants qacH and bcrABC. The presence and distribution of these genes have been anticipated to assume a role in the survival and growth of various microorganisms. It has been described that disinfectants (e.g.benzalkonium chloride) even enhance the growth of Listeria monocytogenes in the food industry.

The use of disinfectants - ostensibly intended to remove/kill pathogens on surfaces which are ubiquitously contaminated with microorganisms - is not reliable anymore [14]. Studies have shown 
that more than one-half the time, microorganisms on these surfaces are not adequately eradicated or surfaces or are recontaminated within minutes. These frequently multiresistant microorganisms are distributed within the hospital by the hands of the personnel to patients. A microbial burden of $>8000 \mathrm{CFU}$ on a $100 \mathrm{~cm}^{2}$ surface is associated with an incidence of $21 \%$ of an hospital acquired infection. In reality we see 100 - 1000 time higher inoculum sizes. [14] Much emphasis has been put therefore on hand disinfection [15]. However, there are also reports of the emergence of alcohol tolerant/insensitive microorganisms e.g. vancomycin resistant enterococci after extensive hand disinfection. This phenomenon has the potential to undermine the effectiveness of alcohol-based disinfectant standard precautions [16-18]. This prompted the WHO to publish a warning of an imminent crisis due to the lack of effective antibiotics and requests immediate, coordinate and ambitious measure. An entirely new approach must be instituted [19].

Considering the above information it was mandatory to reassess preventive measures for hospital acquired infections and to curb the dramatic increasing rate of emerging resistant microorganisms. Antimicrobial coatings hold promise based, in essence, on the application of materials and chemicals with persistent bactericidal or -static properties onto surfaces or in textiles used in the healthcare environments. This belief is based on some preliminary studies involving, for example copper and silver ions, titanium or organosilane, albeit under laboratory conditions. However, the definitive evidence as to their efficacy is still lacking. There are however also several shortcomings of these technologies [20-23]. The development of selfsanitizing surfaces with a broad spectrum of activity, long lasting to permanent antimicrobial activity without induction of resistance seems to be a promising solution for this problem if the requirements for the prevention of hospital acquired infections are met.

The Requirements of Self-Sanitizing Surfaces for Application in Hospitals, Public Transportation, The Food Industry Are Extraordinary High

a. Intensive and broad antimicrobial activity, against Grampositive, Gram-negative microorganisms, irrespective of their antibiotic susceptibility, fungi, legionella, moulds, virus documented by the RODAC plate method

b. Fast eradication of microorganisms i.e. minimum $5 \log 10$ reduction within 1 hour

c. Activity against a high inoculum size of $109 \mathrm{CFU}$ on an area of $3 \mathrm{~cm}^{2}$
d. No induction of resistance
e. Nontoxic, skin and soft tissue compatibility, no allergenicity,
f. Long lasting/permanent antimicrobial activity
g. water-, acid-, alkaline-, alcohol insoluble, UV Light stabile
h. Cleanable with detergents
i. Uncomplicated technical processability, heat stabile up to $400^{\circ} \mathrm{C}$, non-corrosive

j. Physical stability, activity irrespective of sweat, grease, blood, pus

k. Not flammable, smoke reduction

l. BP authorisation by the European commission on biocidal products.

m. Favourable cost/benefit analysis

\section{A Number of Technologies Have Been Proposed}

Active drug eluting agents (e.g. ions or (nano)particles of silver, copper, zinc, or antibiotics, chloride, iodine). Active eluting agents are incorporated into the metabolism of microorganisms and must be eluted from the polymer of the surface: This shows crucial disadvantages: The activity is limited to a short period of time as not sufficient concentrations of silver can be incorporated into a surface. For silver this means a duration of activity of 3 weeks. Copper endowment of a surface has been investigated and preliminary results show a substantial reduction in the number of HAI which establishes the proof of concept. However adverse events have been observed. Besides copper has a

a) a poor antimicrobial activity. This activity is somewhat improved by alloys e.g. combination with zinc or tin but still does not meet the requirements.

b) Copper is cytotoxic if in use for implantable biomaterials.

c) The surfaces are rapidly oxidized and require continuous cleaning.

d) Copper cannot be used in cable insulations

e) Copper cannot be used as transparent coatings of surfaces.

f) Hospital surfaces are preferably white, the color of copper is not accepted by the majority of patients

Other drug eluting agents e.g. Polybiguanides, halogenated phenols, and polyethyleneimines have been immobilized on surfaces but show serious adverse effects on patients.

a) PHMG: Polyhexamethylene guanidine hydrochloride: Severe/lethal pulmonary toxicity of PHMG was discovered [24].

b) HP Halogenated Phenols: Responsible for endocrine and neuronal persistent organic pollutant effects, suspected carcinogen [25]. 
c) PEI Polyethyleneimine is extremely cytotoxic to eucariontes by two different mechanisms: the disruption of the cell membrane leading to necrotic cell death (immediate) and disruption of the mitochondrial membrane after internalisation leading to apoptosis [26]. This approach is also referred to as biomimetic with respect to the activity of chitosan, a polysaccharide derived from exoskeleton of crustaceans or cell walls of fungi. Chitosan, an aminopolysaccharide biopolymer, has a unique chemical structure with a linear polycation with a high charge density, reactive hydroxyl and amino groups as well as extensive hydrogen bonding. It displays good biocompatibility, physical stability and processability. Chitosan is known for its antimicrobial activity by penetration of the cell wall and interaction with DNA, inhibiting DNA transcription and ultimately protein synthesis [27]. However, the application of chitosan is only possibly in the form of nanofibers or nanorods which however cannot be stabile anchored on the surface of e.g. a polymer, glass, stainless steel [28]. Nanoparticles of chitosan cannot be incorporated into polymers [29]. Nanotechnologies are subject to approval by the Biocidal product regulation (BPR) of the European Union. The requirements are time consuming and expensive. None of the nanoproducts passed the biocidal regulation up to this point in time. Nanocoatings are generally not heat resistant, difficult to manufacture and expensive.

\section{Anti-Adhesive - Hyperhydrophobic Surfaces}

Have been designed to reduce the adhesion force between bacteria and a solid surface to enable the easy removal of bacteria before a biofilm layer is formed. Attachment of bacteria or cells starts with an initial adsorption of proteins onto the material surface. Strategies to prevent protein attachment include superhydrophobic surfaces, often augmented by a hierarchical nanostructure as well as zwitterionic polymers. Such surfaces may suppress health care associated infections by blocking transmission paths involving surfaces, but they will not reduce the number of germs on the surface by killing them. For prevention of recontamination of the hands of the personnel, rapid eradication of microorganisms is mandatory [30]. Quaternary ammonium compounds (QAC) must be excluded from considerations as these products may even enhance the growth of listeria monocytogenes on surfaces and induce cross resistance with antibiotics by induction of efflux pumps. QACs are toxic to a lot of aquatic organisms including fish, daphnids, algae, rotifer and microorganisms employed in wastewater treatment systems. Antibiotic resistance has emerged in microorganisms due to excessive use of QACs in household and industrial applications. The occurrence of QACs in the environment is correlated with anthropogenic activities, such as wastewater discharge from Wastewater Treatment Plants (WWTPs) or single source polluters. In addition a number of serious adverse events have been described after uptake e.g. coma, convulsions, hypotension and death, hemolysis, allergies, anaphylactic reactions, contact dermatitis. The mechanism of resistance transferred to antibiotics is due to induction of efflux pumps which covers also the majority of antibiotics [31].

In essence the elution of the antimicrobial compounds necessary for incorporation into the metabolism of microorganisms requires at least a moderate water solubility for biocide release and hence a hydrophilic surface. As the antimicrobial agents must be incorporated into the metabolism of microorganisms, one crucial consequence is the high risk of induction of resistance.

\section{Contact-Active Surfaces}

Exhibit antimicrobial activity without releasing biocidal substances. Several mechanisms are believed to take place in contact-active surfaces. Nanostructures are required, since effective air entrapment in the three-dimensional nanomorphology (nanopillars) renders them superhydrophobic and slippery [32]. On inherently nanostructured hydrophilic aluminium, adhesion forces of bacteria were reduced by a factor of 4 down to $2-4 \mathrm{nN}$ compared to the electropolished flat surface, resulting in an $88 \%$ reduction of colony-forming units (CFUs) for Staphylococcus aureus [32]. This effect was even more pronounced after applying a hydrophobic Teflon coating, yielding a $99.9 \%$ reduction under flow conditions. Nanostructured surfaces were also prepared using electrospun polystyrene nanofibers [33]. With oxygen plasma treatment, a superhydrophilic surface can be generated, which exhibits limited Escherichia coli attachment due to negative zeta potential of -40 mV. After fluorination, a superhydrophobic surface can be obtained, which exhibited self-cleaning ability against bacteria, where the initially adhering bacteria were effectively removed with subsequent washing [34]. This however is not achievable under clinical conditions.

Mechanisms are dependent on:

a. a so-called spacer effect, where the biocidal group is attached to the surface through a polymer chain, allowing the biocide to reach the cytoplasmic membrane of the bacteria and to perforate them [35].

b. alternatively, positively charged QACs, e.g. 3-aminopropyl trimethoxysilane grafted to cellulose nanofibres, can detach phospholipids from the cell membrane and thereby kill the bacteria [36].

The problem which arises with "spacers" is that the activity of the spacer effect is obliterated by grease, proteins, sweat, pus, blood and tensides. As already indicated the consequences of the use of QACs are the induction of resistance genes in bacteria. The activity of chitosan has been investigated and a poor antimicrobial activity has been found. Last not least these compounds are available only as nanostructures which pose serious problems with acceptance as biocidal products. These technologies although attractive from a 
theoretical point of view are not applicable for selfsanitizing surfaces for prevention of hospital acquired infections. It has been suggested to combine two functional principles to achieve synergistic effects, e.g. by embedding biocidal substances into antiadhesive surfaces. Today, the majority of chemical modifications includes hydrogels or polyethylene glycol (PEG) to repel approaching microbes, metals (in particular, silver and copper), antimicrobial peptides (AMPs), quaternary ammonium compounds (QACs), and various nanoparticles [4]. Hydrophobic parts of a surface can act similarly to QACs by deforming the membrane through adhesion. The agents must be insoluble in water-, alcohol-, detergents, acid and alkaline, in addition they must show UV light stability. Antimicrobial agents adjacent to a surfaces have the risk of abrasion with cleaning which is not achievable with the majority of the above mentioned compounds. The topography of a surface can by itself significantly affect its hygienic status, either in a beneficial manner (reducing microbial retention) or otherwise (increasing retention). As such, modifications of surfaces to enhance antimicrobial properties should always take into account the effect of surface wear on subsequent fouling and cleanability. Therefore, efforts should be undertaken to characterize typical wear, assess interactions with the most likely microorganisms in that environment, and define the adverse effects of most appropriate and least damaging cleaning and sanitizing regimes [37].

\section{Anchoring Antimicrobial Agents by Polymer Brushes}

The rationale behind the use of polymer brushes is the observation that antimicrobial molecules lose much of their activity, once attached to a surface. When providing an anchor for the active molecule through a flexible covalently bound polymeric chain, the active molecule should still be able to reach the site of action at or within the bacterium, e.g. by penetrating its cell wall, but leaching is still suppressed. Important parameters for polymer brush anchors are chain length and chain density. Polymer brushes have been shown to be effective for anchoring QACs or AMPs. Antimicrobial peptides (AMP) also known as $B$ defensins are amphophilic, cationic peptides with [38] amino acids, formed by human epithelial cells upon contact with microorganisms. Antimicrobial peptides possessing a net positive charge are attracted and incorporated into negatively charged bacterial membranes. Once inside the membrane, they are believed to cause disruption of the phospholipid bilayer of microorganisms. These amphophilic acid peptides are part of the body's defense mechanisms of the mucosal immunity. The idea behind is attractive: Problems arise with the possible use of AMPs in clinical medicine. AMPs are not easy to be obtained. Embedding of AMPs in a polymer is again not feasible [39].

a) AMPs must be incorporated into the metabolism of microorganisms. In contrast to a publication by Gao AMPs must be eluted from the surface in order to effectively penetrate bacterial membranes. Therefore, the activity is limited to a few days if they are not constantly reproduced by epithelial cells.

b) AMPs are not heat stabile.

c) AMPs are not easy to be obtained. They could be obtained as Magainins from frog skin with very limited availability [40].

d) Formation of AMPs is not feasible as AMPs are lethal factors for microorganisms. Synthesis of antimicrobial peptides has been investigated. Our investigations disclosed that synthetic AMPs induce fast resistance against microorganisms - these microorganisms are in turn also insensitive to natural AMPs produced by the body. AMPs don't withstand cleaning with detergents. Surface-initiated atom transfer radical polymerization (ATRP) has been used to prepare copolymer brushes based on 2-(2-methoxyethoxy) ethyl methacrylate (MEO2MA) and hydroxylterminated oligo(ethylene glycol) methacrylate (HOEGMA) [41]. These coatings were subsequently functionalized by a natural antibacterial peptide, magainin I, via an oriented chemical grafting on hydroxyl groups, which maintains the activity of the peptide. The antibacterial activity of the functionalized brushes was successfully tested against two different strains of gram-positive bacteria. No information is available regarding the duration of activity, resistance to soiling and cleaning. There is no useful clinical application for the use QACs or antimicrobial peptides (AMP) for selfsanitizing surfaces for the prevention of hospital acquired infections. Using surfaceinitiated atom transfer radical polymerization, QACs with charge densities of $>1.5 \mathrm{e} 1015$, accessible quaternary amine units $/ \mathrm{cm}^{2}$ were anchored through poly-2-(dimethylamino) ethyl methacrylate chains. Interestingly, these surfaces were bioactive even though the polymer chains were too short to penetrate the cells with envelope thicknesses of $46 \mathrm{~nm}$ for Gram-negative E. coli and $45.55 \mathrm{~nm}$ for Gram-positive Bacillus subtilis. This demonstrates that surface charge density can be more important than chain length. On the other hand, it was clearly shown that $\mathrm{N}$-alkyl-pyridinium exhibited high antimicrobial activity when anchored through a 750 or 25 $\mathrm{kDa}$ polyethyleneimine (PEI) but showed no activity when using the $2 \mathrm{kDa}$ analogue. Therefore, only long-chained, moderately hydrophobic, immobilized polycations exhibit microbicidal activity. Interestingly, polycationic polymer brushes are not subject to existing mechanisms of resistance such as multidrug- resistance pumps or multidrug tolerance protein-expressing cells, presumably since there are no analogue structures in nature.

Polycations on a surface are not heat resistant and can't be extrusion molded. In addition the activity is obscured by many compounds e.g. grease, sweat, pus, blood proteins etc. which are abundantly coating hospital surfaces close to patients [42]. Besides the technology is complicated and expensive. These compounds can not be added to various coatings. Polymer brushes don't withstand cleaning with detergents or alcohol. Existing antimicrobial modified surfaces suffer from a number of limitations, including the 
rapid release of the adsorbed antimicrobial agent in the first hours after implementation. This results in a relatively short duration of antibacterial activity. Furthermore, cytotoxicity has been reported for silver ions and more so for copper ions on mammalian cells which limits their application. The majority of these technologies don't meet the requirement necessary for the prevention of hospital acquired infections and stop the emergence and spread of multiresistant microorganisms. In addition these technologies show substantial disadvantages: Many of these technologies are toxic and the majority is not approved by the BPR of the European Union. Nanomaterials are available as nanorod or nanomats. Nanocoatings are difficult to fix on surfaces: Their fixation on surfaces is difficult and they loose antimicrobial activity if embedded into composite materials. Approval by the BPR is time consuming and expensive.

Current approaches to decrease microbial contamination on inanimate surfaces are either preventive or biocidal. The first category aims at preventing adhesion of the infectious agents on the surface through an anti-adhesive coating. These include poly(ethylene glycol), diamond-like carbon, self-cleaning surfaces (Lotus effect), and amphophilic polymer coatings. Since the infectious agents are not eradicated, their presence poses still a risk for patients. A more reliable approach is the use of biocidal coatings on materials surfaces [43]. For some of the technologies the mechanism of antimicrobial activity is still under investigation and there is not enough information available on whether antimicrobial activity happens directly at the surface or whether small amounts of the active compounds are released into the test media where they will exert their antimicrobial activity, or whether both mechanisms are acting in parallel. Nanoparticles are frequently constructed but face the problem of approval by regulatory authorities. The spectrum of activity has to be very broad. Surfaces are contaminated with a variety of different microorganisms which affect each other limiting the spread and growth. If only one species is eradicated the remaining microorganisms have the possibility to proliferate and spread uninhibited. Limited spectrum of activity is therefore unacceptable.

These findings underscore the importance of consistently being aware of the types of strains present in an individual clinic over time as well as monitoring the disinfecting regimens that are most effective against the specific strains. Neglecting this type of monitoring may lead to more serious consequences as bacteria acquire more drug-resistant genes or become otherwise tolerant to disinfectants used in hospital settings. As all of the above described technologies did not meet the requirements for successful eradication of microorganisms from contaminated surfaces it was necessary to search for technologies without the above described limitations.

\section{In Situ Generated Biocides by Use of Transition Metal Oxides}

Antimicrobial activity using the concept of Brønsted-Lowry Lewis acids with $\mathrm{MoO}_{3}$ or similar agents. The anti-microbial effect of acids is well known. Hence the idea was to use acidic surfaces for antimicrobial properties imitating the body's own defense mechanisms e.g. acid coating of the skin [44- 46]. Transition metal oxides are eager electron donors: electron transfer occurs to ambient water and results in the formation of various products detrimental to microbes either by deviation from neutral $\mathrm{pH}$, the formation of a variety of free radicals or the formation of a positive Zeta potential and paramagnetic ions. In situ generated biocides by transition metal oxides provide a number of favorable properties required for eradication of microorganisms from surfaces:

1. Formation of an acid surface by formation of $\mathrm{H}^{+}$ions from ambient water. Acid surface $\mathrm{pH}$ : acidification of water molecules - imitating the acid coating of the skin. The surface pH can be investigated by a surface $\mathrm{pH}$ electrode (Sentex) A pH between 4.6 and 4.2 is regularly achieved by transition metal oxides incorporated into a polymer or a coatings on the surface of samples. This corresponds to the $\mathrm{pH}$ of the acid coating of the skin [47]

2. The resulting active substances in addition to acidified water molecules can also be free radicals e.g. oxygen radicals, hydroxyl radicals. There is a synergy on antimicrobial activity by the various mechanisms [48-50].

3. A positive Zeta potential has been observed. A electro positive charge is initiated at the surface which attracts electronegativ charged microorganisms. This results in an almost immediate discharge at the surface and a disruption of the phospholipid bilayer of microorganisms. This is the reason for the rapid bactericidal activity of surfaces [51].

4. Paramagnetic Ions: documented by EPR spectra. have the least clear described antimicrobial activity but contribute to the synergistic activity of the above described technologies.

Most important: No induction of resistance has been observed!

\section{Antimicrobial Surfaces for Health Care Applications Using Transition - Metal Oxides}

It is known that $\mathrm{MoO}_{3}$ reacts with water, e.g. from the ambient air to form $\mathrm{H}^{+}$ions. Therefore, $\mathrm{MoO}_{3}$ incorporation into polymers e.g. thermoplastic polyurethane, silicone and epoxy resin has been useful for the antimicrobial endowment of surfaces. A similar effective antimicrobial activity has been detected by incorporation of tungsten oxides onto polymers. However, the oxygen saturated tungsten yellow oxide shows a low antimicrobial activity in contrast 
to the $5 \%$ oxygen deficient tungsten blue oxide. The principle of the technology is shown in Figure 1. and describes the use of $\mathrm{MoO}_{3}$ for anti-microbial surfaces in thermoplastic polyurethane (TPU).

$$
\mathrm{MoO}_{3}+3 \mathrm{H} 2 \mathrm{O}=2 \mathrm{H}_{3} \mathrm{O}^{+}+\mathrm{MoO}_{4} 2^{-}
$$

In addition also various free radicals (02- , hydroxyl radical, $\bullet \mathrm{OH}$ ) are formed on the surface.

$\mathrm{O}_{2}^{-} \mathrm{H}_{3} \mathrm{O}^{+} \mathrm{H}_{3} \mathrm{O}^{+} \quad \mathrm{O}^{-} \quad \mathrm{H}_{3} \mathrm{O}^{+} \mathrm{H}_{3} \mathrm{O}^{+}$Hydroxyl radicals $\cdot{ }^{\circ} \mathrm{OH} \quad \mathrm{H}_{3} \mathrm{O}^{+}$

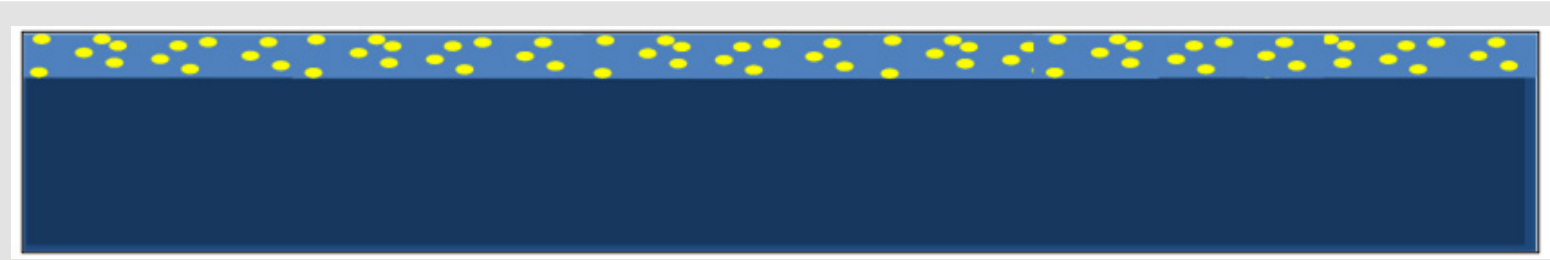

Figure 1: Schematic illustration of the technology: $\mathrm{MoO}_{3}$ (yellow) is embedded in a matrix (blue). At the surface of the compound, germicidal $\mathrm{H}+$ ions will be formed from ambient humidity and various free radicals.

Hydratide Oxonium-Ions, $\left(\mathrm{H}_{3} \mathrm{O}\right)\left(\mathrm{OH}_{2}\right)_{\mathrm{n}} \quad(\mathrm{n}=1,3)$ strip their hydrate water in contact with microorganisms, finally the water molecule. The naked protons penetrate the phospholipid bilayer of bacterial microorganisms by denaturation of the protein envelope. Protons destroy the fimbria preventing adherence of germs on surfaces. Protons also inhibit the activity of vital enzyme systems within the microorganisms which require a narrow $\mathrm{pH}$ environment. This is called protolysis (Coagulation necrosis). Among the various metal oxide semiconductors molybdenum trioxide attracted attention due to its multifaceted functional properties and its application as catalyst in various selected oxidation reactions, sensors and photochromic and electrochromic systems. The photooxidation of water to oxygen and protons in the presence of reducible additives by tungsten has been detected and demonstrated the photocatalytic activity of the powders. In this manner, $\mathrm{WO}_{3}$ is one of the interesting electrochromic inorganic materials. W03 film exhibits a broad range of functional properties, such as small band gap energy $(2.4-2.8 \mathrm{eV})$, deeper valence band $(+3.1 \mathrm{eV})$, stable physicochemical properties, and strong photocorrosion stability in aqueous solution.

The characteristics of $\mathrm{WO}_{3}$ film make them suitable for electrochromic layers e.g. in a smart window. Many studies pertaining to $\mathrm{WO}_{3}$ structures are mainly aimed at the formation of high active surface area in view of their use in electrochromic applications. Zinc molybdate $\left(\mathrm{ZnMoO}_{4}\right)$ crystals again are strong semiconductor inorganic solids and show extensive electronic properties in various scientific fields.

\section{Water Solubility}

$\mathrm{MoO}_{3}$ has a low water solubility, which is even lower when it is incorporated into polymers. Tungsten and its suboxydes are virtually water insoluble. The incorporation of molybdenum trioxide into the tungsten crystal lattice in various concentrations renders also Molybdenum completely water insoluble. Elution experiments of a $100 \mathrm{~cm}^{2}$ surface for 7 days in $1 \mathrm{l}$ of deionized water disclosed $>0.0002 \mathrm{mg} / \mathrm{l}$ of Mo oxide and for Tungsten oxide below the level of detection. This also means a long lasting antimicrobial activity. No toxicity was detected in extensive investigations. Compounds containing Mo oxides and $\mathrm{W}$ oxides in various concentrations in the same crystal lattice are considered a new compound called polyoxometallates with additional properties. Tungsten trioxide and polyoxometallates $\mathrm{Mo}_{\mathrm{x}} \mathrm{W}_{1-\mathrm{x}} \mathrm{O}_{3}$ show similar antimicrobial activity compared to Molybdenum trioxide. This suggested that besides the $\mathrm{H}_{3} \mathrm{O}^{+}$there exist additional mechanisms of antimicrobial activity like paramagnetic $\mathrm{Mo}^{5}$ Ions and a positive Zeta potential. Results of electroparamagnetic resonance (EPR) - spectroscopy support these findings.

\section{Positive Zeta Potential}

\section{Zeta potential}

Zeta potential is a scientific term for electrokinetic potential in colloidal dispersions. The usual units are volts (V) or millivolts $(\mathrm{mV})$. From a theoretical viewpoint, the zeta potential is the electric potential in the interfacial double layer (DL) at the location of the slipping plane relative to a point in the bulk fluid away from the interface. In other words, zeta potential is the potential difference between the dispersion medium and the stationary layer of fluid attached to the dispersed particle. Electronegative charged microorganisms are attracted by the positive surface charge. Upon contact the phospholipid bilayer of microorganisms is disrupted resulting in immediate death of microorganisms. This has been determined by laser scanning microscopy where the death of a large inoculum of microorganisms has been shown within less than 10 minutes. The technology even eliminates microorganisms embedded in a biofilm in contrast to antibiotics and disinfectants.

\section{Paramagnetic Ions}

The EPR spectra obtained indicate that there are considerable concentrations of unpaired spins (i.e. free radicals and also in some cases transition metal ions) present in all of the polymer samples tested. This was observed consistently with all of the samples, with only low levels of unpaired spins seen in the empty tubes. The nature and intensity of the signals vary with the polymer samples 
as would be expected from their different chemical composition and treatments. The yellow tinted mixed oxides $\mathrm{Mo}_{\mathrm{x}} \mathrm{W}_{1-\mathrm{x}} \mathrm{O}_{3}$ contains substantial amounts of $\mathrm{Mo}^{5-}$ Ions. The molar $\mathrm{Mo}^{5-}$ concentration of samples calcinated at 300ㄷ $3 \mathrm{Mo}: 1 \mathrm{~W}$ - and 1Mo:1W-samples are nearly identical. Jet milling in ambient air results in a oxidation of Mo5 to Mo6. The gradation of $\mathrm{Mo}^{5-}$ concentrations in the three tested polyoxometallates is parallel to their antimicrobial activity. The endowment of dyes, lacquers, plastic sufaces with transition metal oxides containing paramagnetic $\mathrm{Mo}^{5-I o n s}$ is an efficient antimicrobial agent nontoxic and noneluting. The same principle is applicable also to the oxygen deficient Tungsten $\mathrm{W}^{5+}$ blue oxide.
All these electrochemical properties/high energy potentials have been found to disrupt the phospholipid bilayer of microorganisms by electron transfer and high voltage surface charges documented by a positive zeta potential and electro paramagnetic properties documented by a high number of electro spins. This suggested that besides the $\mathrm{H}_{3} \mathrm{O}^{+}$there exist additional mechanisms of antimicrobial activity like paramagnetic $\mathrm{Mo}^{5-}$ Ions. Results of electro paramagnetic resonance (EPR) - spectroscopy supports this theory. From $77 \mathrm{~K}$ registered spins per Gram the molar concentration of paramagnetic $\mathrm{Mo}^{5-}$ Ions was calculated. Figure 2. Electron microscopic documentation of the effect of transition metal oxides on microorganisms (S. aureus and E. coli)

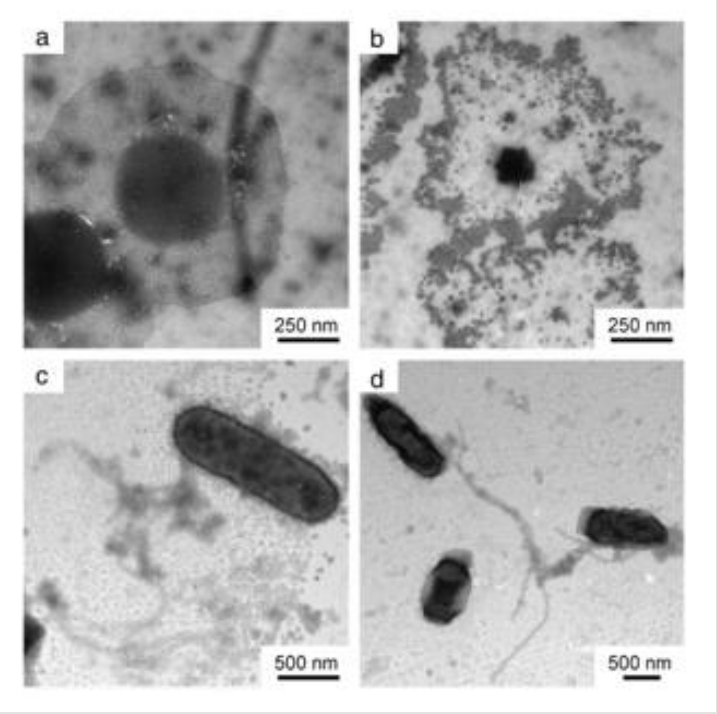

Figure 2: Individual cell of S. aureus on an unmodified surface of polyurethane (PU) (60 min),

a) deteriorated cell of S. aureus on PU tube containing $5.0 \mathrm{wt}$.- $\mathrm{MoO}_{3} 60 \mathrm{~min}$ after incubation intact E. coli. on an unmodified PU surface (10 min)

b) deteriorated cells of E. coli. on a PU surface containing 5.0 wt.- $\mathrm{MoO}_{3} 60$ min after incubation.

\section{Experimental Investigations}

Since the antimicrobial mechanism of in situ generated biocides is non-specific, there is a broad spectrum of activity including Gram positive and Gram negative microorganisms irrespective of their resistance against antibiotics, spores, fungi, Aspergillus spp.,Legionella, viral organisms e.g. influenza (H1N1, H5N1) including enveloped viral pathogens. As the activity is not based on incorporation into the metabolism of microorganisms, bacteria don't develop resistance against this mechanism as is the case with antibiotics and organic biocides. In this work, $\mathrm{MoO}_{3}$ was mixed by $2 \% /-0,1 \%$ (weight) into the thermoplastic polymers TPU, PP and PVC, liquid silicone and epoxy resin. It has to be emphasized that this technology is dependent on a hydrophilic surface. This can be achieved by a number of hydrophilising agents e.g. Glyzerin Stearate 1\% (Atmer) of other compounds like Crodamol, Fleroxacin, Lubropshos again in a $1 \%$ concentration. For different polymers certain hydrophilising agents are preferred and must be investigated accordingly. A contact angle of $30^{\circ}$ or less is mandatory for the antimicrobial activity. The polymer samples were obtained on an extruder (Berstorff ZE25A), and the polymer was shaped into $10 \times 10 \mathrm{~cm}^{2}$ plates using a heated press.

The epoxy resin was a two-component system consisting of 60 parts resin and 40 parts hardener Silicone samples were obtained . The microbiological tests were carried out with $10^{\circ} \mathrm{CFU} / \mathrm{ml}(\mathrm{CFU}=$ colony forming units) of three reference bacteria:

a) Staphylococcus aureus ATCC 25923 (S.a., a typical germ on human skin, Gram-positive) also Enterococci e.g. Strepococcus faecium are within the spectum of activity.

b) Escherichia coli ATCC 25922 (E.c., a typical germ in excrements and a lead indicator for fecal contamination, Gramnegative) 
c) Pseudomonas aeruginosa ATCC 15442 (P.a., a typical germ in air, soil and water, Gram-negative)

d) Carbapenem resistant Klebsiella spp. just as numerous other multiresistant Gram negative microorganisms (e.g. Acinetobacter Baumannii, Serratia marcescens) are also covered by the spectrum of activity.

e) Similar experiments have been performed with 180 fresh clinical isolates isolated from hospital acquired infections. The determination of anti-microbial effectiveness was done by the push plate method and the roll-out method, which are costeffective and semi-quantitative tests resembling the "real life situation".

f) Also Legionella spp, Candida spp, are included in the spectrum of activity.

g) Polyoxometallates show also strong activity against Aspergillus spp. like A. fumigatius and A. niger.

h) Activity of transition metal oxides (Zinc Molybdate) against a number of viral pathogens has been demonstrated (bird flu, swine flu, Influenza, Herpes virus, Respiratory syncytial virus, Epstein Barr Virus, EBV)

Polyoxometallates show strong activity against bacterial microorganisms and excellent activity against molds. Also additional virus e.g. the eneveloped Hepatitis B and C are included in the spectrum of activity. As polyoxometallates are also active against enveloped viral pathogens it is investigated now also against coronavirus. In the literature an efficacy of polyoxometallates with a titanium doped polyoxometallate on a surface against corona viruses is already described by $\mathrm{Hu}$ et al. POM's [alphaPTi(2)W(10)O(40)](7-) titanium is used to form an electrostatic potential at the surface and free radicals such as oxygen radicals to enhance the effectiveness of polyoxometalates. Polyoxometalates with a molybdenum oxide doping shows stronger efficacy in comparison with the Titanium doped polyoxometallate: this is the formation of a stronger acid surface, higher concentrations of free radicals and above all a substantially stronger zeta potential. The paramolybdotungstate with the formula is $\left[\mathrm{H}_{2} \mathrm{Mo}_{6} \mathrm{~W}_{6} \mathrm{O}_{42}\right]^{10}$ can be produced as the compounds assemble by themselves due to their similar ion radius. In addition also activity against a variety of sweet water and sea water algae. Samples containing $2 \%$ of polyoxometallates are free of algae during a 2 years observation period after immersion in sea water and sweet water in contrast to controls which were coated with algae within 2 weeks. These polyoxometalates can either be incorporated into a polymer surface or into a transparent coating e.g. liquid polyurethane, liquid silicone and other coating materials such as paints, which dry within one hour.

\section{Various Products of Transition Metal Oxides Are Available With Similar Antimicrobial Activity And Can Be Used According To The Characteristic Properties}

\section{Molybdenum Trioxide $\mathrm{MoO}_{3}$}

Molybdenum trioxide is available as a light blue/gray powder with particle size of $2-5 \mu \mathrm{m}$

A. Advantage: strong antimicrobial activity with addition of $2 \%$ to various polymers e.g. TPU for ECG lead wires which has been documented in numerous experiments. Thermal induced fracturing of the hydrates of molybdenum trioxide retains the orthorhombic crystal structure with particle sizes of $0.2 \mu \mathrm{m}$. (Lambda half) The incorporation in various coatings e.g. liquid silicone results in a transparent antimicrobial addition to glass and stainless steel. Acid surfaces formed by Brønsted-Lowry acids already prevent effectively adherence of microorganisms on surfaces, block proliferation and biofilm formation.

The powder is inexpensive and available in unlimited quantities.

B. Disadvantage: Molybdenum trioxide shows a water solubility of $0.003 \mathrm{~mol} / \mathrm{l}$ at a $\mathrm{pH}$ value $>7.45$. Elution experiments of a $100 \mathrm{~cm}^{2}$ TPU surface containing $2 \% \mathrm{MoO}_{3}$ for 7 days in $1 \mathrm{l}$ of deionized water disclosed a concentration of $0.0002 \mathrm{mg} / \mathrm{l}$ of Mo and tungsten below the level of detection. Molybdenum oxides are not UV light stable. The safety data sheet shows cancerogenicity: A detailed evaluation of the data has shown that cancerogenicity is seen after inhalation of $100 \mathrm{mg} / \mathrm{m} 3$ of submicron particles over a period of 6 hours/day 5 days per week for 2 years in rats. $50 \%$ of rats were affected by pulmonary malignancy, no mice were affected by the same study protocol. Molybdenum oxides incorporated into composite materials e.g. TPU, silicone, lacquers or various coatings are not present as submicron particles. In the rare case that molybdenum oxides are eluted from a polymer although the water solubility of molybdenum oxides, incorporated into composite materials is exceedingly low, Molybdates and not molybdenum oxides are eluted. Molybdates dont show cancerogenicity. This however is of relevance for masterbatch production. A dustfree application of Molybdenum oxides into composite materials is required but state is considered of the art. The toxicity of Molybdenum is remarkable low. It has to be emphasized that molybdenum - as well as zinc are essential trace elements in the body. Molybdenum is a stabilising molecule in several enzymes important to animal and plant metabolism for elimination of sulfur from the body:

1. Sulfite oxidase catalyses the oxidation of sulfite to sulfate, necessary for metabolism of sulfur amino acids. Sulfite oxidase deficiency or absence leads to neurological symptoms and early death. 
2. Xanthine oxidase catalyses oxidative hydroxylation of purines and pyridines including conversion of hypoxanthine to xanthine and xanthine to uric acid.

3. Aldehyde oxidase oxidises purines, pyrimidines, pteridines and is involved in nicotinic acid metabolism.

4. Low dietary molybdenum leads to low urinary and serum uric acid concentrations and excessive xanthine excretion.

5. Molybdenum functions as an electron carrier in those enzymes that catalyse the reduction of nitrogen and nitrate.

Two 13-wk studies were conducted by the national toxicology program (NTP, 1997) in which F-344/N rats and B6C3F1 mice $(10 /$ sex/group) were exposed to molybdenum trioxide for $6.5 \mathrm{hr} / \mathrm{d}, 5$ $\mathrm{d} / \mathrm{wk}$ at concentrations of $0,1,3,10,30$, or $100 \mathrm{mg} / \mathrm{m}^{3}$. All rats and mice survived to the end of the study. Significant increases in liver copper concentrations were observed in female mice exposed to $30 \mathrm{mg} / \mathrm{m} 3$ and in male and female mice exposed to $100 \mathrm{mg} / \mathrm{m}^{3}$ (males: $11.51 \mu \mathrm{g} / \mathrm{g}$ in the $100-\mathrm{mg} / \mathrm{m} 3$ exposure group versus 8.19 $\mu \mathrm{g} / \mathrm{g}$ in controls; females: 6.51 and $6.98 \mu / \mathrm{g}$ in the 30 -and 100 $\mathrm{mg} / \mathrm{m}^{3}$ dose groups, respectively, versus $5.68 \mu / \mathrm{g}$ in controls). The increased copper concentrations were not regarded as being an adverse effect relevant for deriving a LOAEL and a NOAEL. No other clinical findings were observed in either rats or mice. Additionally, no significant differences in absolute or relative organ weights, sperm counts, or motility were noted in rats or mice. In the same NTP (National Toxicology Program,) study 1997, rats (F344/N) and mice $\left(\mathrm{B}_{6} \mathrm{C}_{3} \mathrm{~F}_{1}\right)(50 / \mathrm{sex} /$ dose $)$ exposed for $6 \mathrm{hr} / \mathrm{d}, 5 \mathrm{~d} / \mathrm{wk}$ at concentrations of $0,10,30$, or $100 \mathrm{mg} / \mathrm{m}^{3}$ molybdenum trioxide for $2 \mathrm{yr}$ experienced a significant exposure-dependent increase in blood Mo concentrations. Male and female rats exposed to 30 or $100 \mathrm{mg} / \mathrm{m}^{3}$ experienced significantly increased incidences of chronic alveolar inflammation.

Incidences of hyaline degeneration in the nasal respiratory epithelium in male rats exposed to 30 or $100 \mathrm{mg} / \mathrm{m}^{3}$ and in all exposed groups of females rats were significantly greater than those of the control groups. Incidences of hyaline degeneration in the nasal olfactory epithelium of all exposed groups of females were also statistically significant. For male mice, the incidences of histiocyte cellular infiltration in all exposed groups were significant. Incidences of hyaline degeneration of the respiratory epithelium of the nasal cavity in female mice at $100 \mathrm{mg} / \mathrm{m}^{3}$ were significantly greater than those in the controls (NTP 1997). Based on the 2-yr NTP study, the LOAEL is $10 \mathrm{mg} / \mathrm{m}^{3}$ for increased incidences of hyaline degeneration in the nasal respiratory epithelium and nasal olfactory epithelium in female rats. Hazard statements for Molybdenum powder: Causes eye irritation. May cause respiratory irritation. Precautionary statement: Wear protective gloves/ protective clothing/ eye protection/ face protection. Molybdenum trioxide is not UV light stabile. Molybdenum trioxide can be used for an antimicrobial activity of any surface which is not in constant water contact. The light blue color can not be concealed by additional color pigments.

\section{Tungsten Trioxide $\mathrm{WO}_{3}$}

Tungsten Trioxide has been investigated for in situ generated biocidal activity. Initial experiments with the oxygen saturated Tungsten yellow oxide disclosed limited antimicrobial activity. Further investigations disclosed that the oxygen deficient tungsten blue oxide W02.75-2.90 shows antimicrobial activity comparable to Molybdenum trioxide. Tungsten trioxide is a dark blue powder and is available with $5 \mu \mathrm{m}$ particle size.

Advantage: Tungsten blue oxide is completely water insoluble, the safety data sheet shows no adverse reactions except for necessary individual contact measures. Again this is of relevance to the masterbatch producer as tungsten trioxide is not released from polymers or coatings. Tungsten blue oxide can be used for surfaces in permanent contact with water e.g. pipes. Tungsten blue oxide is a suitable addition to kautschuk e.g. for siderails in escalators.

\section{Zinc Molybdate $\mathrm{MoO}_{4} \mathrm{Zn}$}

The combination of Molybdenum trioxide with Zinc oxide in the same crystal structure in a triclinic orthorhombic crystal structure shows excellent antimicrobial activity plus additional features. For endowment of various polymers e.g. melamin resin, TPU, Silicone where a white color is mandatory, zinc molybdate is an excellent choice. Zinc molybdate is neither water nor alcohol soluble and stays firmly inside a polymer or paint. It is not toxic and can be used as a corrosion prevention agent, a flame retardant and smoke suppressant compound. Zinc Molybdate is UV light stabile. The strength of the antimicrobial activity is comparable with Molybdenum trioxide with activity against Gram positive and Gram negative microorganisms, legionella, spores and fungi. In addition also influenza virus (bird flu, swine flu) is included in the spectrum of activity. Zinc molybdate is UV light stabile, non toxic. Zinc molybdate is available in $2 \mu \mathrm{m}, 5 \mu \mathrm{m}$ and $8 \mu \mathrm{m}$ particles sizes. Zinc Molybdate can also be synthesized as $0.2 \mu \mathrm{m}$ particles in fluids in unlimited quantities.

There are 3 possible sources

1. Ultrasound treatment of Zinc oxide and ammonium dimolybdate (Bhanvase)

2. Atlas Syrris Synthesis reactor

3. Pharmjet by Nanosaar

Zinc Molybdate has a broad spectrum of applications e.g. in hospital furniture and in any polymer where a white color is mandatory. Flame retardant/smoke suppressant properties make Zink Molybdate suitable for application in airplanes but 
also in trains and public transportation-.Zinc Molybdate can also be used for heat exchange equipment in airconditioners in cars. Most uses are for paints (paints for NMR, angiography systems, C bows and CT scanners) Hospital furniture. Coating is available for Hospital interiors, restaurants, kitchen, food production sites. No carcinogenicity is described. Skin tolerance test have been performed of lacquer samples with Zinc molybdate incorporated in a concentration 0.25 and $1 \%$ : In 10 persons skin tolerance tests have been performed with a $5 \times 5 \mathrm{~cm}$ lacquer sample of Zinc Molybdate $1 \%$ over a period of 24, 48, 72 and 120 hours on their forearm in a wet chamber. No adverse effects have been seen during the test period. No allergy was observed during one year 1 year following the initial observation.

\section{Polyoxometallates, $\left[\mathrm{H} 2 \mathrm{Mo}_{6} \mathrm{~W}_{6} \mathrm{O}_{4} 2\right]^{10-}$}

The observation of a moderate water solubility of Molybdenum trioxide prompted the development of polyoxometallates i.e. incorporation of the Molybdenum trioxide into the tungsten trioxide crystal lattice. Polyoxometallates are available by commercial producers e.g. in unlimited quantities.

Polyoxometallates can also be synthesized by the Pharmjet (additional investigative work on the basis of limited preliminary results)

\section{A. Advantage:}

1. Water insolubility of molybdenum in the combined crystal lattice.

2. Additional strength of antimicrobial activity against Gram positive and Gram negative microorganisms due to a strong Zeta potential

3. Additional antimicrobial activity against molds (Aspergillus spp)

4. Activity against a number of virus (influenza, hepatitis $B$, C, Flavivirus, HIV, RSV, RNA Virus, (EBV), Herpes simplex as well as Norovirus.

\section{Activity against algae, antifouling activity}

These properties recommend the use of polyoxomtallates as addition to filter systems in airconditioners and many other applications. The product passed the EN14476 (liquid disinfectant test) in 2 hours with a $4 \log$ reduction and the treated surfaces killed 98\% more than the control surface in 2 hours.

\section{Additional Remarks}

All the above mentioned additives as powder with particle sizes of $2-8 \mu \mathrm{m}$ can be added to various polymers e.g. TPU, PE PP, HDPE, Polystyrol, Polyimine, silicone. The surface has to be wettable with y contact angle of $30^{\circ}$. This can be achieved by the addition of hydrophilising agents (preferably Glyzerin Stearat and others e.g. Crodamol, Fleroxacin, Lubrophos in a concentration of
$1 \%)$. Smaller particles $(0.2 \mu \mathrm{m}$ particles sizes $)$ can be produced by thermal induced fractioring or by synthesis which preserves the crystal structure (orthorhombic and monocline) required for antimicrobial activity. Submicron particles embedded into transparent coatings are used for transparent antimicrobial activity on glass (Figure S1).

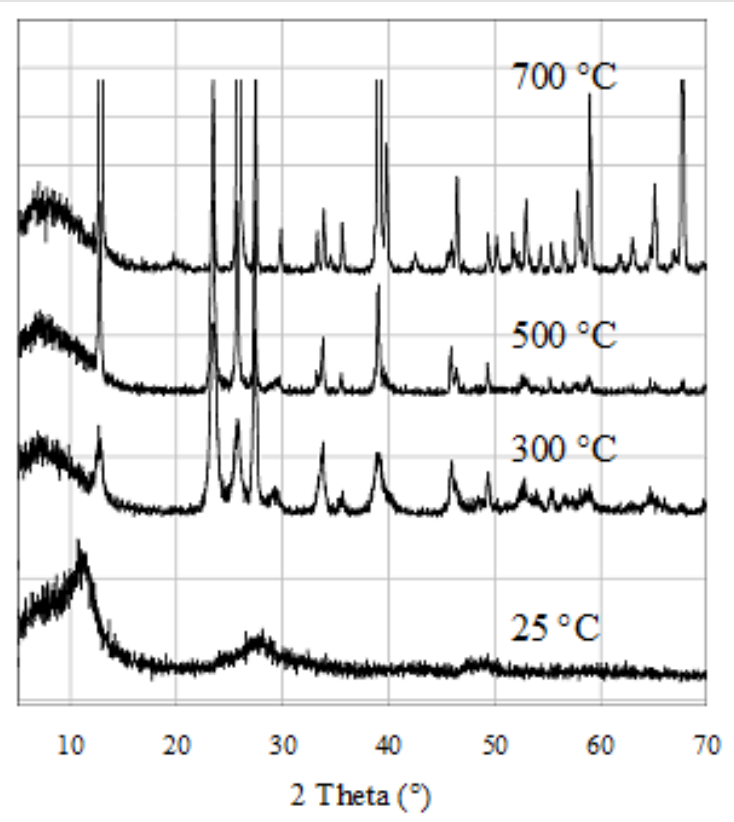

Figure S1: XRD diagrams of the as-prepared $\mathrm{MoO}_{3}$ based gel and after annealing at various temperatures.

\section{Experimental Investigations}

The investigations for antimicrobial activity have been performed with two test systems

a. JIS method

b. RODAC - push plate method

JIS method (Japanese industrial standard) (Figure 3) testing is required by the biocidal product regulation (BPR) of the Eurpean Union. However, this method is far from the real life situation, therefore the investigations have been performed according to the RODAC plate method. RODAC (Replicate Organism Detection and Counting) pushplate method (b): Microorganisms (ATCC reference strains) are stored in cryopellets at $-25^{\circ} \mathrm{C}$. Prior to the investigations pellets are grown in isosensitest broth for $6-8$ hours. In the evening microorganisms are transferred from liquid medium to blood agarplates with the addition of $5 \%$ defibrinated sheep blood at $37^{\circ} \mathrm{C}$. "overnight cultures". After 12 hours colonies are harvested and suspended in Aqua bidestillata at a final concentration of $109 \mathrm{CFU} / \mathrm{ml}$. The number of colony forming units per $\mathrm{ml}$ is evaluated by a photometric method: an OD of 0.33 at $475 \mathrm{~nm}$ reveals a concentration of $109 \mathrm{CFU} / \mathrm{ml}$ of Staphylococcus aureus. Final concentrations were determined by several 1:10 dilutions until colonies were countable. 


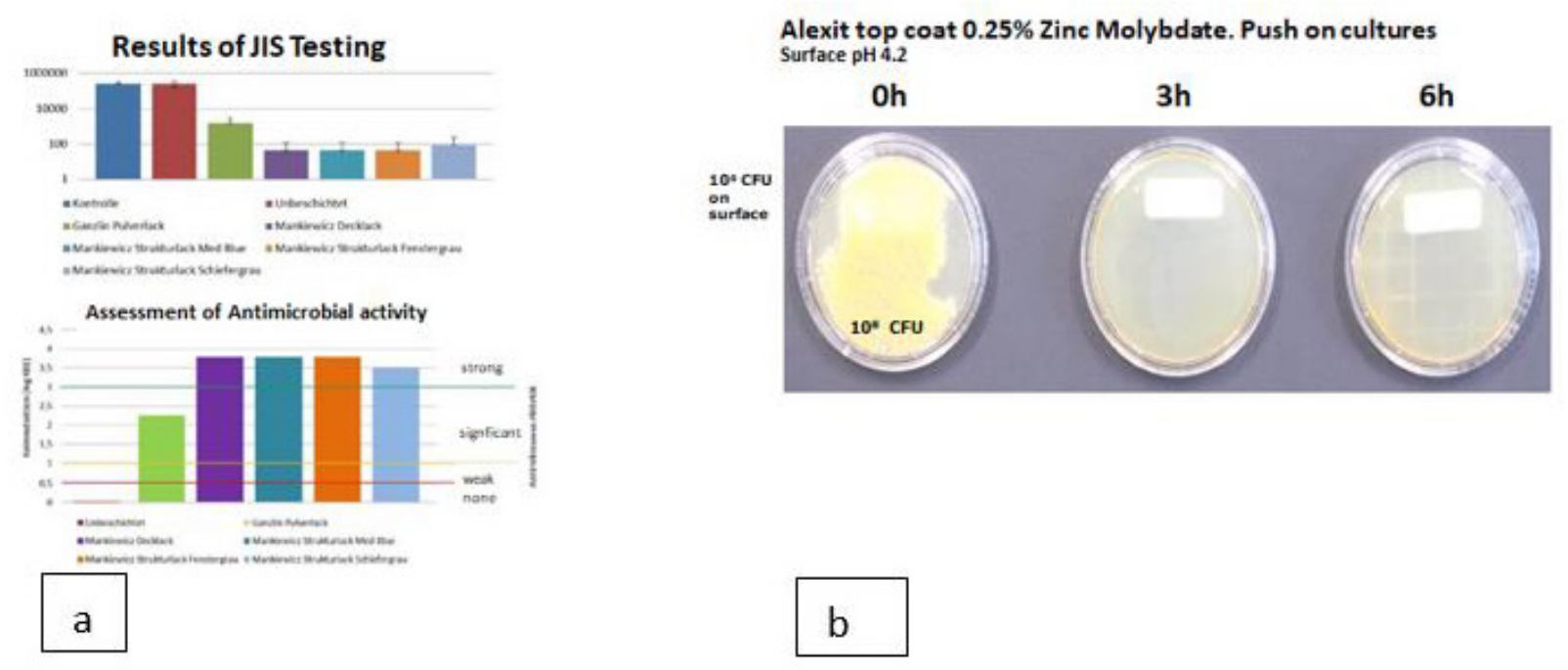

Figure 3: Investigation of laquer samples by the JIS method (a) and the RODAC push plate method (b)

$10 \mu \mathrm{l}$ of the bacterial suspension containing $109 \mathrm{CFU} / \mathrm{ml}$ is applied to a $1 \mathrm{~cm}^{2}$ surface of the material to under investigation. The drops are dispersed over an area of $1 \times 2.5 \mathrm{~cm}$ with a Drigalski spatula. The liquid dries on the surface within 15 minutes. From the initial inoculum ( 0 hour) after one hour and in three hourly intervals thereafter until 12 hours RODAC Plates Caso Agar with "Enthemmer" are pressed onto the contaminated areas. The push plates are incubated at $37^{\circ} \mathrm{C}$ for 24 hours. Then colonies are counted, the results are documented by photography. Investigation of antimicrobial activity investigation has also been performed after hand contamination of surfaces similar to a real life situation.
It has been demonstrated that an assumed contamination with 109 $\mathrm{CFU} / \mathrm{ml}$ (lawn) is eradicated within 30 minutes. Polyoxometallates show also a reduction of the original inoculum size of $7 \log 10$ within less than 3 hours of Aspergillus spp. and algae [54]. Samples of TPU and PP containing $2 \%$ polyoxometallates in the polymer are 3 years after immersion in a pond containing an abundance of algae free of contamination in contrast to a control sample which was contaminated within 7 days. The spectrum of activity of polyoxometallates also contains a number of virus e.g. Hepatitis B, Hepatitis C, RNA Virus, Herpesvirus and HIV (Figure 4).

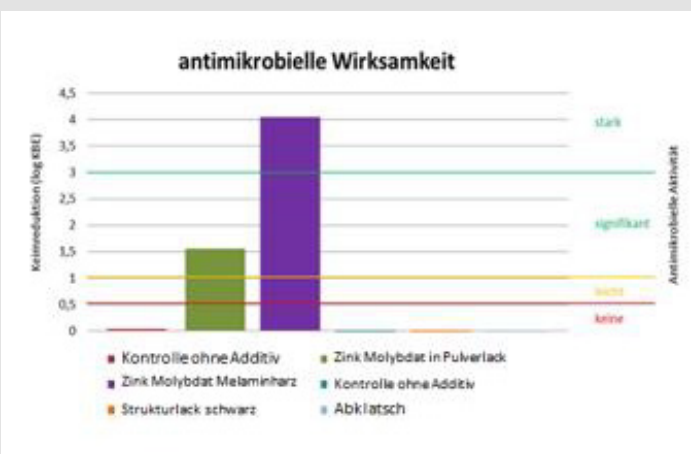

\section{a}

Figure 4: Investigation of melamin resin on hospital furniture by the JIS method (a) and the RODAC push plate method.
Hospital furniture Surface pH 4.0

Melaminresin: Staphylococcus aureus ATCC 25723

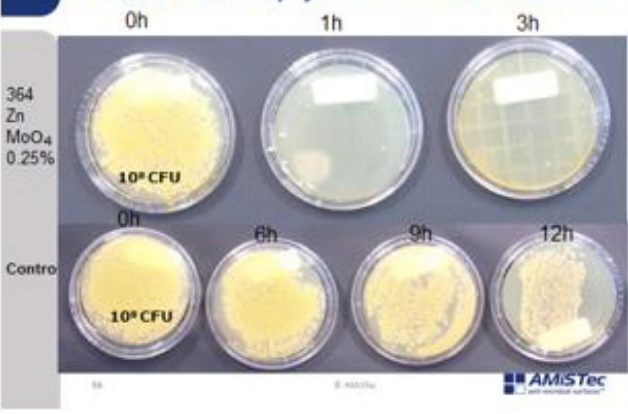

b 


\section{Technical Application}

Transition metal oxides can be incorporated into various polymers and coatings e.g. liquid silicone, liquid poyurethane, silicium dioxide. It is essential that the surface is hydrophilic i.e. wettable with a contact angle of $30^{\circ}$ or less. This is possible by the addition of various hydrophilising agents e.g. 1\% glycerine stearate or Crodamol., Fleroxacin, Lubrophos. The hydrophilising agents have to be adapted to the polymer. Antimicrobial cables have been produced by incorporation of $2 \%$ Molybdenum Trioxyd in thermoplastic polyurethane which is already sufficient hydrophilic on the surface. The investigation of antimicrobial activity has been performed by the rollon culture technique. $5 \mathrm{~cm}$ pieces of cable containing $2 \%$ of molybdenum trioxide have been immersed into a suspension of S. aureus ATCC 25923 in a concentration of 109 $\mathrm{CFU} / \mathrm{ml}$ for 6 hours. Thereafter the pieces have been rolled over an agar plate (Oxoid Agar containing $5 \%$ sheepblood) Then sample has been added to a sterile empty Saarsted vial. This procedure has been repeated in 3 hourly intervals until 12 hours. It has been shown that the initially contaminated samples did not contain any microorganisms after 3 hours and thereafter. In an additional experiment samples of cables produced in 2002 have been investigated with the same method. These 18 years old samples showed identical results compared to the original samples (Figure 5).

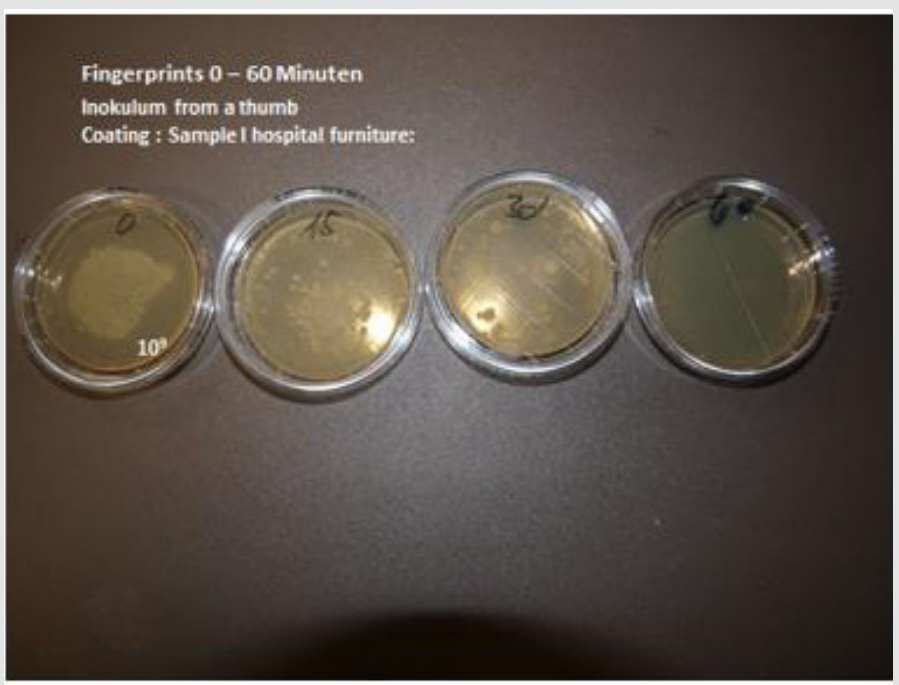

Figure 5: Antimicrobial activity of hospital furniture after hand contamination 0 until 30 minutes. Microorganisms are eradicated within 30 minutes.

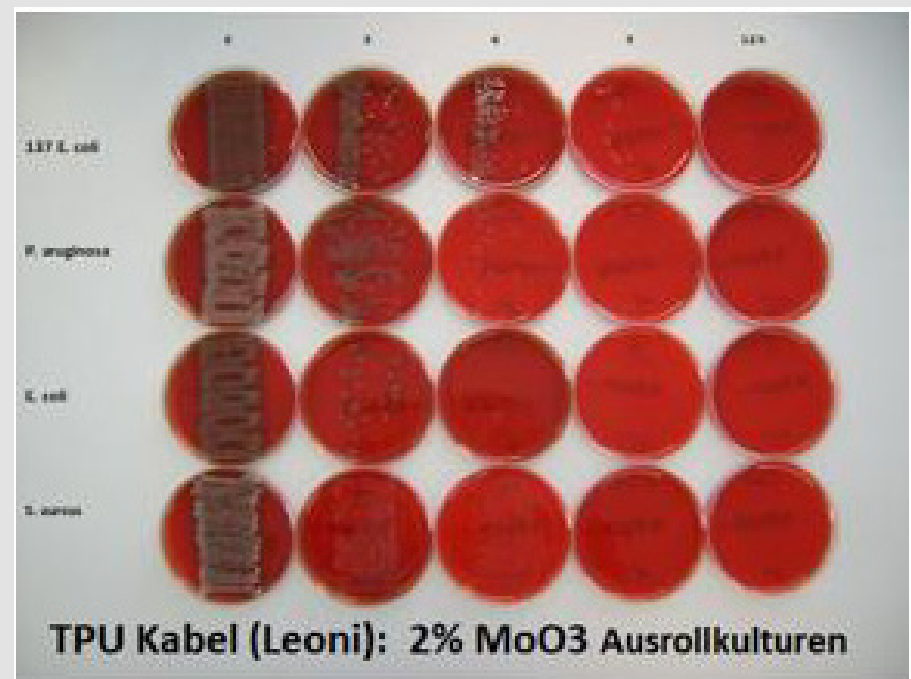

Figure 6: Roll on culture results of a ECG lead wire. SOP described above. 
Transition metal oxides can be incorporated in various composite materials or coatings (liquid Silicone, liquid polyurethane, Silicium Dioxyd). These coatings containing $0.25 \%$ Zink Molybdate in liquid silicone and liquid polyurethane (Coating I, Coating II) have been investigated with the push plate (RODAC plate) method compared with a negative control. The reduction of colony forming units constitutes $7 \log 10$ within 1 hour. As test organism S. aureus ATCC 25923 has been used. Many of the samples have also been investigated by the JIS 25923 method. (Figure 6) All results obtained with the RODAC push plate method were also confirmed by the JIS 25923 method. Documentation by external laboratories used the JIS method and confirmed the antimicrobial activity. Various technical application of Zink Molybdat, $\mathrm{MoO}_{3}$ and $\mathrm{WO}_{3}$ in ultrathin transparent layers on glass, ceramic, stainless steel, enamel have been used by vapor deposition, (CVD), spray pyrolysis and Sol-Gel-techniques. Sol-Gel- techniques have been empolyed, which resulted in ultrathin films at room temperature. Investigations demonstrated excellent antimicrobial efficacy [43].

\section{Toxicologic Investigations and Biocompatibility}

Lacquer samples (100 $\mathrm{cm}^{2}$ containing $0.25 \%$ Zink-Molybdate) have been wiped with a textile 10000 times with watern, alcohol, detergent. The textile has been investigated by the „spectroturboquant-powder" method. No elution of the additive from the sample has been detected (Figure 7) Table 1.
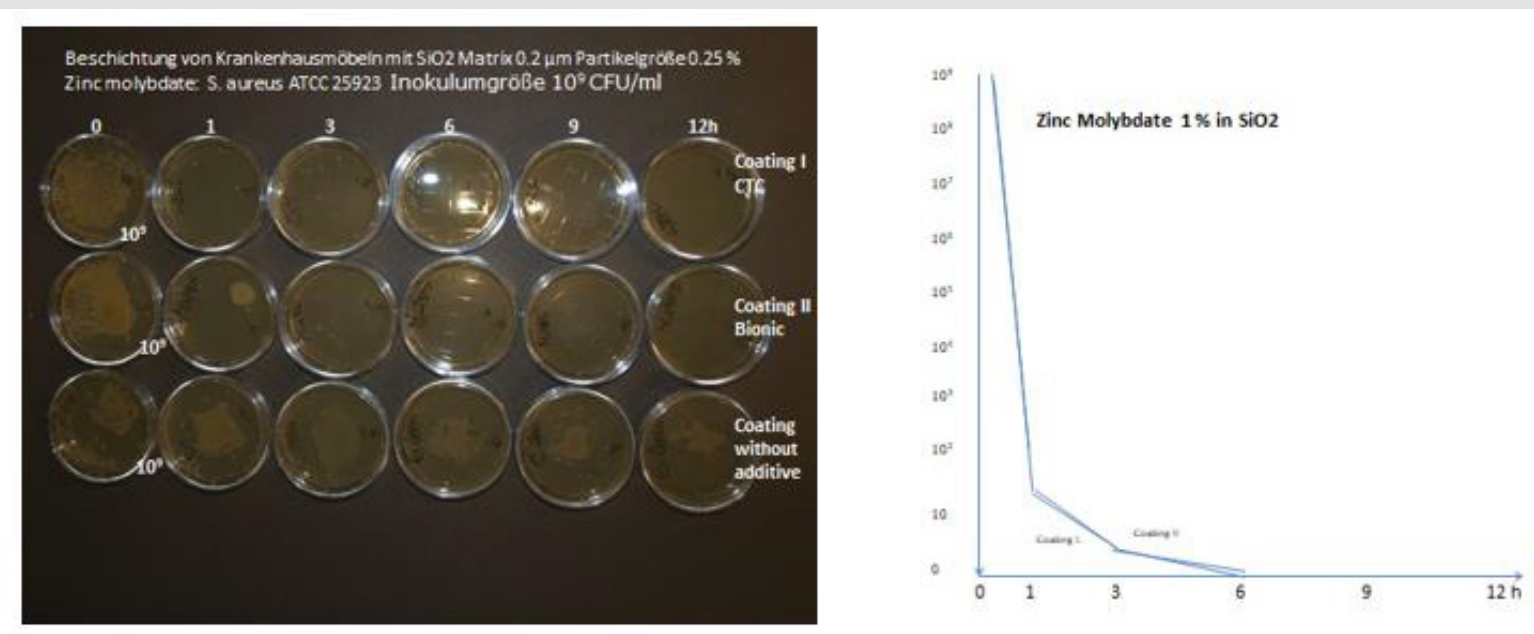

Figure 7: Investigation of coatings from two companies: The coatings is silicium dioxide with incorporation of $0.25 \%$ Zinc Molybdate each, particle size $0.2 \mu \mathrm{m}$ S. aureus ATCC 25923.

Table 1: Toxicologic investigations and biocompatibility.

\begin{tabular}{|c|c|}
\hline Textile After $\mathbf{1 0 0 0}$ Wipes & Control Textile \\
\hline $\mathrm{Mg}<0.01 \%$ & $\mathrm{Mg}<0.01 \%$ \\
\hline $\mathrm{Al}<0.01 \%$ & $\mathrm{Al}<0.01 \%$ \\
\hline $\mathrm{Si} 2.66 \%$ & $\mathrm{Si} 1.63 \%$ \\
\hline $\mathrm{P} 0.01 \%$ & $\mathrm{P} 0.02 \%$ \\
\hline $\mathrm{S} 0.27 \%$ & $\mathrm{~S} 0.23 \%$ \\
\hline $\mathrm{Cl} 0.45 \%$ & $\mathrm{Cl} 0.26 \%$ \\
\hline $\mathrm{K} 0.03 \%$ & $\mathrm{~K} 0.13 \%$ \\
\hline $\mathrm{Ca} 0.14 \%$ & $\mathrm{Ca} 0.12 \%$ \\
\hline $\mathrm{Ti} 0.05 \%$ & $\mathrm{Ti} 0.06 \%$ \\
\hline $\mathrm{V}<0.01 \%$ & $\mathrm{~V}<0.01 \%$ \\
\hline $\mathrm{Cr}<0.01 \%$ & $\mathrm{Cr}<0.01 \%$ \\
\hline $\mathrm{Mn}<0.01 \%$ & $\mathrm{Mn}<0.01 \%$ \\
\hline $\mathrm{Fe} 0.02 \%$ & $\mathrm{Fe} 0.02 \%$ \\
\hline $\mathrm{Ni}<0.01 \%$ & $\mathrm{Ni}<0.01 \%$ \\
\hline $\mathrm{Cu} 0.03 \%$ & $\mathrm{Cu} 0.03 \%$ \\
\hline $\mathrm{Zn}<0.01 \%$ & $\mathrm{Zn}<0.01 \%$ \\
\hline $\mathrm{Mo}<0.01 \%$ & $\mathrm{Mo}<0.01 \%$ \\
\hline
\end{tabular}

\section{Solubility Experiments Of Mo And W In Epoxy Resin And TPU“}

One important requirement is the insolubility of Molybdenum (VI)-oxid as well as the Tungsten(VI)-oxides in water, alcohol and detergents. For Molybdenum oxid a water solubility of $0.003 \mathrm{~mol} / \mathrm{l}$ at a $\mathrm{pH}$ value $>7.55$ has been described. Experiments documented that there is no drop of $\mathrm{pH}$ within 28 days in water after immersion of e.g. catheters or ECG cables containing $5 \% \mathrm{MoO}_{3}$ or $\mathrm{WO}_{3}$ in the composite material (TPU). In alkaline $\mathrm{pH}$ ( $\mathrm{pH}$ value $>>9$ ) a solubility exists with elution of Molybdates and Wolframates. The investigations regarding the solubility of Molybdenum trioxide and Tungsten trioxide have been performed with ICP-OES using two wavelengts Mo (313.259nm and 379.825nm) and $W(224.875 \mathrm{~nm}$ und $276.427 \mathrm{~nm}$ ) on the basis of linear calibrations. Initially experiments have been planned for a 24h/RT elution. As no measurable concentrations have been detected the elution time was extended to 1 week. There was the assumption that an equilibrium between the additive and the solvent (water) would be established within this week. The concentrations of transition metal oxides in various samples has been investigated by spectro turboquant 
analysis after a 10 days elution in deionised water. In each sample the concentration has been below the limit of detection of von $0.005 \mathrm{mg} / \mathrm{l}$. in no instance the concentration was above the limit of detection. Investigations also disclosed that tungsten compounds are completely insoluble in water and alcohol values are consistently below $0.002 \mathrm{mg} / \mathrm{l}$. To solve the problem with water solubility of molybdenum oxides molybdenbum trioxide has been incorporated into the tungsten crystal lattice revealing a new compound referred as polyoxometallates with additional antimicrobial properties. The unique properties besides the know activity against all bacterial microorganisms contained in the spectrum of molybdenum trioxide are the activity against Aspergillus spp and several viral pathogens. There is also a strong antifouling activity.

\section{Investigation of Cytotoxicity}

Cables containing $5 \% \mathrm{MoO}_{3}$ in TPU and $10 \times 10 \mathrm{~cm}$ plates containing $1 \%$ Zinc Molybdate in melamine resin were eluted 10 days in deionised water. Repeated investigations of cytotoxicity disclosed the survival of the MRC 5 cells (mouse lung fibroblast cell line) in these solutions. Cytotoxicity was also investigated by the Nitroblue tetrazolium test (NBT Test) where the transparent pharmazan is transformed by oxygen radicals into nitro blue tetrazolium. Vital cells form oxygen radicals as a determination of the lack of cytotoxicity. No difference between control samples without the additives and verum samples containing $1-2 \%$ of transition metal oxides has been seen. It has also been documented that various cell lines e.g. verocells, osteoblasts, epithelial cell line also survive on surfaces containing $0.25 \%$ Zink Molybdat as well as $5 \%$ Molybdenum oxide and are viable for minimum 2 months.

It has to be emphasized that molybdenum as well as Zinc are essential trace elements in the body. These transition metal oxides are stabilising enzyme systems for detoxification and alimination of sulfur which is contained in various amino acids e.g. Cystin, Cystein und Methionin from the body.

1. Sulfite oxidase catalyses the oxidation of Sulfit to Sulfat,

2. Xanthine oxidase catalyses the oxidative hydroxylation of Purines and Pyridines including the metabolism of hypoxanthin to Xanthine and Xanthine to urea.

\section{Aldehyd Oxidase oxidases Purines, Pyrimidines, Pteridines.}

4. Last not least Molybdenum catalysis nitrat to nitrit which can be used by plants.

Limits of intake of Molybdenum is defined by: www.efsa. europa.eu/de/ndatopics/docs/ndatolerableuil.pdf This provides an UL [upper limit] of $0.01 \mathrm{mg} / \mathrm{kg} \mathrm{Bw} /$ day, which also covers pregnant and lactating women, equivalent to $0.6 \mathrm{mg} /$ person/day for adults,". In no instance the limits have been reached. In essence exposition of humans to samples endowed with transition metal oxides remained 100 times below the allowed concentrations.
Skin tolerance has been investigated in 10 testpersons. $10 \times 10$ cm metal plates with a lacquer containing $0.25 \%$ Zink Molybdat have been applied during 120 hours at the forearm of 10 adult persons in a moist chamber. No adverse reactions, no reddening, itching, scaling has been observed. There was no allergenicity during the observation of the next 6 months This is of no surprise as the normal $\mathrm{pH}$ of the skin is in a range of $4.6-5.0$ similar to the $\mathrm{pH}$ value of the surface of the lacquer sample. Extensive additional investigations have been performed with various composite materials containing $5 \%$ und $10 \% \mathrm{MoO}_{3}$ e.g. aging investigations over 9 months at $75{ }^{\circ} \mathrm{C}$. The antimicrobial activity has been unchanged. Also the elasticity, kinking stability, tensile strength was unchanged.

Dose efficacy investigations have been performed. Good activity is seen at $0.5 \%$ of the additive for the majority of applications. If thin coatings (less than $100 \mu \mathrm{m}$ ) are used a concentration of the additive of $0.2 \%$ is sufficient. The best activity for example for addition of Molybdenum into thermoplastic polyurethane is $2 \%$. Higher concentrations don't result in increased antimicrobial activity. We can summarise that this new innovative technology provides a highly efficient endowment of surfaces with antimicrobial activity against a groad spectrum of Gram positive and Gram negative microorganism fungi and virus. The activity is independent on existing resistance against antibiotics and disinfectants, a reduction of an inoculum of $109 \mathrm{CFU} / \mathrm{ml}$ of $7 \log ^{10}$ is seen within less than 1 hour. The activity is lasting for documented more than 10 years. In contrast to disinfectants no induction of resistance is observed. Transition metal oxides show an effective locally confined antimicrobial efficiacy. The technology exhibits a very broad and fast antimicrobial activity against Gram positive, Gram negative microorganisms irrespective of their resistance against antibiotics, fungi including Aspergillus spp, many virus e.g. bird flu, swine flu, influenza, Metal oxides don't induce resistance as these substances attack microorganisms from the outside and are not incorporated into the metabolism of microorganisms.

Therefore no induction or selection of resistant microorganisms is observed. Transition metal oxides are not eluted from the surface of polymers. As a consequence the antimicrobial activity lasts a minimum of documented 10 years with regular cleaning cycles. The technology is not toxic and biocompatible. In essence the additives are essential trace elements in the body. Skin tolerance has been investigated over 120 hours without adverse events. No allergy has been observed during the following 12 months. The additives and be applied to various composite materials e.g. TPU, PE, PP, It is also possible to endow the additives into various coatings e.g. liquid silicone, liquid polyurethane and silicium dioxide. It has to be ensured that the surface is hydrophilic with a contact angle of $30^{\circ}$ or less. With a particle size of $<0.2 \mu \mathrm{m}$ also a transparent surface can be achieved. The technology is highly cost effective. Investigations with artificial aging over 90 days at $75^{\circ} \mathrm{C}$ temperature, exposure to an acid pH 2.0 or alkaline $\mathrm{pH} 9.5$ for 5 weeks at $75^{\circ} \mathrm{C}$, exposure to 
tap water over 6 months with continuous exchange of the eluent, exposure to $90 \%$ alcohol for 6 hours did not result in any decrease of antimicrobial activity.

\section{Toxicologic Assessment of Transition Metal Oxides}

Molybdenum Trioxide $\mathbf{M o O}$ : Molybdenum trioxide is a light gray powder with particle sizes of $2-5 \mu \mathrm{m}$. Of crucial importance for the antimicrobial activity of Molybdenum trioxide is the correct crystal structure: The crystal structure is monoclinic and orthorhombic. This has to be confirmed by $\mathrm{x}$ ray diffraction investigations.

A. Advantage: strong antimicrobial activity with addition of $2 \%$ in various composiite materials, e.g. in TPU for ECG lead wires which show a high rate of contamination and biofilm formation. Excellent antimicrobial efficacy in various other polymers has been documented. Molybdenum trioxide powder is cost efficient and available in unlimited quantities. Molybdenum is an essential trace element [40].

B. Disadvantage: Molybdenum is water soluble with $0.003 \mathrm{~mol} / \mathrm{l}$ at a $\mathrm{pH}$ value $>7.45$ at room temperature. Elution experiments of a $100 \mathrm{~cm}^{2}$ TPU surface endowed with $2 \% \mathrm{MoO}^{3}$ during 7 days in $1 \mathrm{l}$ deionised water show an elution of $>0.0002$ $\mathrm{mg} / \mathrm{l}$. Similar investigations with tungsten blue oxide show also concentrations below the level of detection. Molydenum however is in contrast to Zinc Molybdate or tungsten blue oxide not UV light stabile. The safety data sheet of Molybdenum trioxide shows carcinogenicity: Rats and mice have been exposed to 30 or 100 $\mathrm{mg} / \mathrm{m}^{3}$ body weight of ultrafine powder by inhalation 6 hours a day, 5 days per week over 2 years. In $50 \%$ of the rats pulmonary malignancy was observed. Mice in contrast did not show malignant transformations. It hast to be emphasized that cancerogenicity has been observed by inhalation of ultrafine powder which is not present if Molybdenun is incorporated into composite materials or coatings (liquid silicone or liquid polyurethane) as no elution has been observed from these polymers.

Fairhall et al. exposed rats to inhalation of submicron particles of $\mathrm{CaMoO}^{4}\left(125 \mathrm{mg} \mathrm{Mo} / \mathrm{m}^{3}\right.$ ) for $1 \mathrm{hr} / \mathrm{d}, 5 \mathrm{~d} / \mathrm{wk}$ for 5 weeks. It was observed that $5 / 24$ guinea pigs died following exposure but no other signs of toxicity were observed. Guinea pigs (51 animals, sex not reported), who were exposed to $250 \mathrm{mg} \mathrm{MoO}^{3} / \mathrm{m}^{3}$ (164 mg Mo/ $\mathrm{m}^{3}$ ) using the same exposure regime, experienced severe eye and nasal irritation, loss of appetite and weight, diarrhea, muscular incoordination, and loss of hair. Following the $10^{\text {th }}$ exposure, 26/51 animals died. Inhalation of $195 \mathrm{mg} / \mathrm{m}^{3}$ two 13 -wk studies were conducted by NTP (1997) in which F-344/N rats and B6C3F1 mice (10/sex/group) were exposed to molybdenum trioxide for $6.5 \mathrm{hr} / \mathrm{d}$, $5 \mathrm{~d} /$ wk at concentrations of $0,1,3,10,30$, or $100 \mathrm{mg} / \mathrm{m} 3$. All rats and mice survived to the end of the study. Significant increases in liver copper concentrations were observed in female mice exposed to $30 \mathrm{mg} / \mathrm{m} 3$ and in male and female mice exposed to $100 \mathrm{mg} / \mathrm{m}^{3}$ (males: $11.51 \mu \mathrm{g} / \mathrm{g}$ in the $100-\mathrm{mg} / \mathrm{m}^{3}$ exposure group versus 8.19 $\mu \mathrm{g} / \mathrm{g}$ in controls; females: 6.51 and $6.98 \mu / \mathrm{g}$ in the 30 -and 100 $\mathrm{mg} / \mathrm{m}^{3}$ dose groups, respectively, versus $5.68 \mu / \mathrm{g}$ in controls). The increased copper concentrations were not regarded as being an adverse effect relevant for deriving a LOAEL and a NOAEL. No other clinical findings were observed in either rats or mice. Additionally, no significant differences in absolute or relative organ weights, sperm counts, or motility were noted in rats or mice.

In the NTP study (1997), rats (F344/N) and mice (B6C3F1) (50/sex/ dose) were exposed for $6 \mathrm{hr} / \mathrm{d}, 5 \mathrm{~d} / \mathrm{wk}$ at concentrations of $0,10,30$, or $100 \mathrm{mg} / \mathrm{m} 3$ molybdenum trioxide for $2 \mathrm{yr}$ experienced a significant exposure-dependent increase in blood Mo concentrations. Male and female rats exposed to 30 or $100 \mathrm{mg} / \mathrm{m} 3$ experienced significantly increased incidences of chronic alveolar inflammation. Incidences of hyaline degeneration in the nasal respiratory epithelium in male rats exposed to 30 or $100 \mathrm{mg} / \mathrm{m} 3$ and in all exposed groups of females rats were significantly greater than those of the control groups. Incidences of hyaline degeneration in the nasal olfactory epithelium of all exposed groups of females were also statistically significant. For male mice, the incidences of histiocyte cellular infiltration in all exposed groups were significant. Incidences of hyaline degeneration of the respiratory epithelium of the nasal cavity in female mice at $100 \mathrm{mg} / \mathrm{m} 3$ were significantly greater than those in the controls (NTP 1997). Based on the 2-yr NTP study, the LOAEL is $10 \mathrm{mg} / \mathrm{m} 3$ for increased incidences of hyaline degeneration in the nasal respiratory epithelium and nasal olfactory epithelium in female rats. It has to be emphasized, that during the manufacturing process inhalation of submicron particles however is possible for employees. Precautions have to be established to prevent inhalation which is general state of the art in a manufacturing process.

Wolfram Trioxyd $\mathbf{W O}_{3}$ : Tungsten trioxide has been investigated for its antimicrobial activity. Initially the investigations have been performed with the oxygen saturated tungsten yellow oxide or a unknown contamination of the Tungsten yellow oxide with Tungsten blue oxid. Poor antimicrobial activity has been observed. Further investigations however disclosed that the pure $5 \%$ oxygen deficient tungsten blue oxide W02.75-2.90 shows a strong antimicrobial activity which correlated with a strong electron release of tungsten from composite materials. Tungsten blue oxide is a dark blue powder with particle sizes of $5 \mu \mathrm{m}$. By „thermal induced fracturing“ the particle size can be reduced to 0,25 $\mu \mathrm{m}$. By these means also transparent surfaces in combination with transparent coatings (liquid Silicon, liquid Polyurethane) can be constructed. The advantage of tungsten blue oxide is the complete water insolubility. The safety data sheet does not disclose special precautions: Industrially Tungsten trioxide does not constitute an important health hazard. Operating facilities should be operated according to the related handling safety. The protection of persons 
and health management indicate no ingestion of the compound Mist protective equipment is required to wear for prevention of inhalation. Hand protection and eye protection is not required: Popular work clothes are acceptable. Effects of overexposure: exposure is related chiefly to the dust arising out of the crushing and milling operations. Chronic inhalation of the dust may cause lung damage in humans. Carcinogenic assessment is not listed

Zinc Molybdate $\mathbf{M o O}_{4} \mathbf{Z n}$ : Moybdenum oxide as well as Tungsten blue oxide have a light blue (Molybdenum) or dark blue color which is not suitable e.g for Hospital furniture. Molybdenum oxide in a zink oxide crystal lattice has a white colour and shows equal antimicrobial activity compared to molybdenum oxide. The spectrum of activity is comparable. In addition a number of viral agents e.g. influenza virus are in the spectrum of activity. The crystal lattice has to be triclinic and orthorhombic. Zink Molybdate is water and alcohol insoluble, UV light stabile and has smoke suppressant and has flame inhibitory properties. Zink Molybdate is used as an anticorrosive agent. It can be added to various polymers e.g. melamin resin for hospital furniture but also in numerous coatings. Various pigments can be added to Zinc Molybdate to achieve every desired colour. Submicron particles in transparent coatings result in a transparent lamination of stainless steel and glass. Zinc molybdate is available as $2 \mu \mathrm{m}, 5 \mu \mathrm{m}$ and $8 \mu \mathrm{m}$ particle sizes. Submicron particles of Zink Molybdate partikel $(0.2 \mu \mathrm{m})$ can be produced by synthesis. Various chemical engineering processes for synthesis are available.

The white color or the transparent coatings recommend Zinc Moylbdate for a broad spectrum of applications. The flame retardent and smoke suppressant properties recommend Zinc Molybdate for the use in public transportation in airplanes, trains and cars. Zinc Molybdate can used for corrosion free application of heat exchangers in air conditioners etc. The toxicity of Zinc Molybdate has been investigated intensively. No side effects have been described. No carcinogenicity is known.

Polyoxometallates, $\quad\left[\mathbf{H}_{2} \mathbf{M o}_{6} \mathbf{W}_{6} \mathbf{O}_{42}\right]^{10_{-}:}$The fact that molybdenum shows a minimal but measurable water solubility prompted further investigations. Molybdenum trioxide is incorporated into the tungsten crystal lattice and revealed a new compound referred as polyoxometallates with additional antimicrobial properties. The unique properties are besides the know activity against all bacterial microorganisms contained in the spectrum of molybdenum trioxide are activity against Aspergillus spp. also activity against algae and several enveloped virus e.g. hepatitis B, C, Flavivirus, HIV, RSV, RNA Viren, EpsteinBarr virus (EBV), Herpes simplex not contained in the spectrum of Molybdenum trioxide or Zinc Molybdate. The compound is completely insoluble in water and alcohol. The strong zeta potetial is resposible for the rapid eradication of microorganisms. A reduction of $7 \log 10$ within 15 minutes has been documented by laser scanning microscopy. Polyoxometallates are eradicating also microorgansims contained in biofilms which can not be achieved by antibiotics and disinfectants.

In the literature an effectiveness of polyoxometallates with a titanium doping on a surface against corona viruses has been already described Hu et al. POM's [alpha-PTi(2)W(10)O(40)](7-) titanium is used to form an electrostatic potential at the surface and free radicals such as oxygen radicals to enhance the effectiveness of polyoxometalates. However, titanium is cancerogenic and is therefore not suitable for use on surfaces that many people are exposed to. As a better alternative, other polyoxometalates have been produced using a combination of molybdenum oxide incorporated into the tungsten oxide crystal lattice, which has a stronger zeta potential and also increased formation of free radicals. The formula of paramolybdotungstate is $\left[\mathrm{H}_{2} \mathrm{Mo}_{6} \mathrm{~W}_{6} \mathrm{O}_{42}\right]^{10}$ and is produced in our laboratory. Antifouling activity has been documented. The application of the above described technology for self sanitizing surfaces is nearly unlimited. An important indication for selfsanitizing surfaces are hospitals e.g. hospital furniture, push buttons and control knobs for ventilators and infusion pumps, ECG lead wires, oxygen monitors, textiles, light switches and door handles. The technology is also suitable for endowment of surfaces in CF scans, nuclear magnetic resonance machines and angiography systems to save the use of disinfectants. Also implantable biomaterials e.g. urologic catheters, endotracheal tubes and central venous catheters, antimicrobial suture material can benefit from the addition of transition metal oxides to the polymer. Selfsanitizing surfaces are also of advantage in nursing homes., hotels and restaurants.

A special application of this technology is dentistry e.g. coating of dental implants and prostheses as well as the coating of equipment preventing contamination with Hepatitis B and C. The technology is also suitable for antimicrobial paints and coatings for medical equipment e.g. implantable biomaterials, CT scanners, anaesthetic machines, nuclear magnetic resonance imaging, angiography systems, $\mathrm{X}$ ray equipment, endoscopes etc. The technology is also mandatory for germfree surfaces in public transportation, airplanes, trains and trolleys, cockpits of cars e.g. in car sharing. Multiresistant microorganisms prevalent in Asean countries are distributed worldwide by airplanes, distributed by tourists in trains, trolleys, cruse ships and restaurants. The technology is also used in food production and storage e.g. kitchens and restaurants where disinfectants can be saved. The technology with polyoxometallates should be used on tubings of aircondition systems against Aspergillus spp. which have a potential for allergisation.

\section{Patent Protection}

The technology of in situ generated biocides is worldwide patent protected. According to the intended use and the specific 
requirements one of the four additves (Molybdenum oxide, tungsten blue oixide., Zinc molybdate or Polyoxometallates can be used. The transition metal oxides can be incorporated into various composite materials or coatings e.g. liquid silicone, liquid polyuethane or silicium dioxide or in transparent coatings of glass for computer screens and keyboards, telefons including handy and stainless steel surfaces.

\section{References}

1. Ahonen M, Kahru A, Ivask A. Kaja Kasemets 5, Siiri Kõljalg, et al. (2017) Proactive approach for safe use of antimicrobial coatings in healthcare settings: Opinion of the cost action network AMiCI. International Journal of Environmental Research and Public Health 14(4):366.

2. Vincent JL, Rello J, Marshall J, Silva E, Anzueto A, et al. (2009) EPIC Il Group of Investigators. International study of the prevalence and outcomes of infection in intensive care units. JAMA 302(21): 2323-2329.

3. National Nosocomial Infections Surveillance (NNIS) Report, data summary from January 1992 to June 2002 issued August 2002. Am Infect Contr 30(8): 458 -475.

4. Klevens RM, Edwards JR, Richards CL, Jr Horan TC, Gaynes RP, et al. (2007) Estimating healthcare-associated infections in US hospitals, 2002. Public Health Rep 122(2): 160-166.

5. Roberts RR, Scott RD, Hota B, Kampe LM, Abbasi F, et al. (2010) Costs attributable to healthcare-acquired infection in hospitalized adults and a comparison of economic methods. Med Care Nov 48(11):1026-1035.

6. Fair R, Tor Y (2014) Antibiotics and Bacterial Resistance in the 21st Century. Perspect Medicine Chem. 6: 25-64

7. Report: Prof. Dr. John Walker at the yearly nobel laureate meeting Lindau Germany August 2018. Spiegel online 2018.

8. Limayem A, Martin EM (2014) Quantitative risk analysis for potentially resistant E. coli in surface waters caused by antibiotic use in agricultural systems. J Environ Sci Health B 49(2): 124-133.

9. Bridier A, Briandet R, Thomas V, Dubois-Brissonnet (2019) Resistance of bacterial biofilm on disinfectants: a review. Biofouling The Journal of Bioadhesion and Biofilm Research 27(9): 22 -34.

10. Williamson KS, Richards LA, Perez-Osorio AC, Pitts B, McInnerney K, et al. (2012) Heterogeneity in Pseudomonas aeruginosa biofilms includes expression of ribosome hibernation factors in the antibiotic-tolerant subpopulation and hypoxia-induced stress response in the metabolically active population. J Bacteriol. 194(8): 2062-2073.

11. Zhang Y, Gu AZ, He M, Li D, Chen J (2017) Subinhibitory Concentrations of Disinfectants Promote the Horizontal Transfer of Multidrug Resistance Genes within and across Genera. Environ Sci Technol 51(1): 570-580.

12. Otter JA, Yezli S, Salkeld J.A.G, French GL (2013) Evidence that contaminated surfaces contribute to the transmission of hospital pathogens and an overview of strategies to address contaminated surfaces in hospital settings Am J Infect Control. Supplement: 41(5): S6S11.

13. Møretrø T, Schirmer BCT, Heir E, Fagerlund A, Hjemli P, et al. (2017) Tolerance to quaternary ammonium compound disinfectants may enhance growth of Listeria monocytogenes in the food industry. Int J Food Microbiol. 241: 215-224.

14. Boyce JM, Pittet D (2002) Healthcare Infection Control Practices Advisory Committee Guideline for Hand Hygiene in Health care settings. Recommendations of the Health care Infection control Practices Advisory Committee and the HICPAC/SHEA/APIC/IDSA Hand Hygiene Task Force. Society of the Healthcare Epidemiology of America / Association of Professionals in Infection Control/Infectious Diseases Society of America. MMWR Recomm Rep. 51(RR-16): 1-45.
15. Haft RJ, Keating DH, Schwaegler T, Schwalbach MS, Vinokur J, et al. (2014) Correcting direct effects of ethanol on translation and transcription machinery confers ethanol tolerance in bacteria. Proc Natl Acad Sci U S A 111(25).

16. Lusta KA, Leonovitch OA, Tolstorukov II, Rabinovich YM (2000) Constitutive biosynthesis and localization of alcohol oxidase in the ethanol-insensitive catabolite repression mutant ecr1 of the yeast Pichia methanolica. Biochemistry (Mosc) 65(5): 604-608.

17. Deutsches Ärzteblatt (2019) Antibiotikaresistenzen: Expertengruppe der Vereinten Nationen schlägt Alarm.

18. Murray J, Muruko T, Gill CIR, Kearney MP, Farren D, et al. (2017) Evaluation of bactericidal and anti-biofilm properties of a novel surfaceactive organosilane biocide against healthcare associated pathogens and Pseudomonas aeruginosa biolfilm. PLoS One 12(8).

19. Hsueh YH, Tsai PH, Lin KS (2017) pH-Dependent antimicrobial Properties of Copper Oxide Nanoparticles in Staphylococcus aureus. Int J Mol Sci 18(4): 793

20. Guggenbichler JP, Böswald M, Lugauer S, Krall T (1999) A new technology of microdispersed silver in polyurethane induces antimicrobial activity in central venous catheters. Infection 27 Suppl 1: S16-23.

21. Mijnendonckx K, Leys N, Mahillon J, Silver S, Van Houdt R, et al. (2013) Antimicrobial silver: uses, toxicity and potential for resistance. Biometals 26(4): 609-621.

22. Asiedu-Gyekye I, Mahmood AS, Nyarko A (2015) Toxicological assessment of polyhexamethylene biguanide for water treatment. Interdiscip Toxicol 8(4): 193-202.

23. Montaño M, Gutleb AC, Murk AJ (2013) Persistent toxic burdens of halogenated phenolic compounds in humans and wildlife. Environ Sci Technol 47(12): 6071-6081.

24. Kafil V, Omidi Y (2011) Cytotoxic Impacts of Linear and Branched Polyethylenimine Nanostructures in A431 Cells. Bioimpacts 1(1): 23-30.

25. Archana D, Dutta J, Dutta PK (2013) Evaluation of chitosan nano dressing for wound healing: characterization, in vitro and in vivo studies. Int J Biol Macromol 57: 193-203

26. Radulescu M, Ficai D, Oprea O, Ficai A, Andronescu E, et al. (2015) Antimicrobial Chitosan based formulations with impact on different biomedical applications. Curr Pharm Biotechnol 16(2): 128-136.

27. Archana D, Dutta J, Dutta PK (2013) Evaluation of chitosan nano dressing for wound healing: characterization, in vitro and in vivo studies. Int J Biol Macromol 57: 193-203.

28. Muszanska AK, Rochford ET, Gruszka A, Bastian AA, et al. (2014) Antiadhesive polymer brush coating functionalized with antimicrobial and RGD peptides to reduce biofilm formation and enhance tissue integration. Biomacromolecules 15: 2019-2026.

29. Blair JM, Richmond GE, Piddock LJ (2014) Multidrug efflux pumps in Gram-negative bacteria and their role in antibiotic resistance. Future Microbiol 9(10): 1165-1177.

30. Hizal F, Rungraeng N, Lee J, Jun S, Busscher HJ, et al. (2017) Nanoengineered Superhydrophobic Surfaces of Aluminum with Extremely Low Bacterial Adhesivity. ACS Appl Mater Interfaces 9(13): 12118-12129.

31. Saini S, Belgacem MN, Salon M-CB, Bras J (2016) Non leaching biomimetic antimicrobial surfaces via surface functionalisation of cellulose nanofibers with aminosilane. Cellulose 23: 795-810.

32. Novotny JA, Peterson CA. Molybdenum (2018) a trace element essential for humans, plants, and animals. Adv Nutr 9(3): 272-273.

33. Ganz T (2003) Defensins: antimicrobial peptides of innate immunity. Nat Rev Immunol 3 (9): 710-720. 
34. Zasloff M (1987) Magainins a class of antimicrobial peptides from Xenopus skin: isolation, characterization of two active forms, and partial cDNA sequence of a precursor. Proc Natl Acad Sci 84(15): 5449-5453.

35. Xu J, Fan X, Yang J, Ma C, Ye X, (2014) Poly (1-lactide-co-2-(2methoxyethoxy(ethyl methacrylate): a biodegradable polymer with protein resistance. Colloids Surf. B Biointerfaces 116: 531-536.

36. Hunter AC (2006) "Molecular hurdles in polyfectin design and mechanistic background to polycation induced cytotoxicity". Advanced Drug Delivery Reviews 58 (14): 1523-1531.

37. Tiller JC, Liao CJ, Lewis K, Klibanov AM (2001) Designing surfaces that kill bacteria on contact. Proc Natl Acad Sci U S A 98: 5981-5985.

38. Zollfrank C, Gutbrod K, Wechsler P, Guggenbichler JP (2012) Antimicrobial activity of transition metal acid $\mathrm{MoO}(3)$ prevents microbial growth on material surfaces. Mater Sci Eng C Mater Biol Appl 32(1): 47-54.

39. Lackner M, Maninger S, Guggenbichler JP (2013) Saure Oberflächen als neuartige Kontaktbiozide. Nachr Chem 61(2):112-115.

40. Zollfrank C, Gutbrod K, Wechsler P, Guggenbichler JP (2012) Antimicrobial activity of transition metal acid $\mathrm{MoO}_{3}$ prevents microbial growth on material surfaces. Mater Sci Eng C Mater Biol 32(1): 47-54.

41. B0оTH I R (1985) Regulation of Cytoplasmic $\mathrm{pH}$ in Bacteria. Microbiological Reviews 49(4): 359-378.

42. Mimic-Oka J, Simic D V, Simic T P (1999) “Free radicals in cardiovascular diseases," The scientific journal Facta Universitatis Series: Medicine and Biology 6(1): 11-22.

43. Vatansever F, de Melo WC, Avci P, Vecchio D, Sadasivam M, et al. (2013) Antimicrobial strategies centered around reactive oxygen species-bactericidal antibiotics, photodynamic therapy and beyond. FEMS Microbiol Rev 37(6): 955-989.

\section{ISSN: 2574-1241}

DOI: $10.26717 /$ BJSTR.2020.30.004967

Guggenbichler JP. Biomed J Sci \& Tech Res

This work is licensed under Creative Commons Attribution 4.0 License

Submission Link: https://biomedres.us/submit-manuscript.php
44. Nakamura K, Shirato M, Kanno T, Örtengren U, Lingström P, et al. (2016) Antimicrobial activity of hydroxyl radicals generated by hydrogen peroxide photolysis against Streptococcus mutans biofilm. Int J Antimicrob Agents 48(4): 373-380.

45. Delgado AV, Gonzalez-Caballero F, Hunter RJ, Koopal LK, Lyklema J, et al. (2005) "Measurement and Interpretation of Electrokinetic Phenomena" (IUPAC Technical Report). Pure Appl. Chem 77 (10): 1753-1850.

46. Shafaei S, Van Opdenbosch D, Fey T, Koch M, Kraus T, et al. (2016) Enhancement of the antimicrobial properties of orthorhombic molybdenum trioxide by thermal induced fracturing of the hydrates. Mater Sci Eng C Mater Biol Appl 58: 1064-1070.

47. (2014) Toxicologial Risks of selected flame-Retardant Chemicals. National Academiec Press.

48. Fukuma M, Seto Y, Yamase T (1991) In vitro antiviral activity of polyoxotungstate (PM-19) and other polyoxometalates against herpes simplex virus. Antiviral Res 16(4): 327-339.

49. Schoeberl C, Boehner R, Krebs B, Mueller C, Barnekow A, et al. (1998) A new polyoxometalate complex inhibits retrovirus encoded reverse transcriptase activity in vitro and in vivo. Int J Oncol 153-162.

50. Sammit Karekar, Bharat A. Bhanvase, S. H. Sonawane, Manik P Deosarkar, (2014) Synthesis of Zinc Molybdate and Zinc phosphomolybdate by an ultrasound assisted route: advantage over conventional methods. Bhanvase B.A. Chemical engineering and processing.

51. Hu D, Shao C, Guan W, Su Z, Sun J, et al. (2007) Studies on the interactions of Ti-containing polyoxometalates (POMs) with SARS-CoV 3CLpro by molecular modeling. J Inorg Biochem 101(1): 89-94. 